\title{
ASSESSING TEMPORAL COMPLEMENTARITY BETWEEN THREE VARIABLE ENERGY SOURCES BY MEANS OF CORRELATION AND COMPROMISE PROGRAMMING
}

\section{A PREPRINT}

\author{
Fausto A. Canales \\ Department of Civil and Environmental \\ Universidad de la Costa \\ Barranquilla, Colombia
}

\author{
Jakub Jurasz \\ School of Business Society and Engineering \\ MDH University, \\ Västerås, Sweden \\ and \\ Department of Engineering Management \\ AGH University \\ Krakow, Poland
}

\author{
Alexander Kies \\ Frankfurt Institute for Advanced Studies \\ Goethe University Frankfurt \\ Frankfurt am Main, Germany
}

May 2, 2019

\begin{abstract}
Renewable energies are deployed worldwide to mitigate climate change and push power systems towards sustainability. However, the weather-dependent nature of renewable energy sources often hinders their integration to national grids. Combining different sources to profit from beneficial complementarity has often been proposed as a partial solution to overcome these issues. This paper introduces a novel method for quantifying total temporal energetic complementarity between three different variable renewable sources, based on well-known mathematical techniques: correlation coefficients and compromise programming. It has the major advantage of allowing the simultaneous assessment of partial and total complementarity. The method is employed to study the complementarity of wind, solar and hydro resources on different temporal scales in a region of Poland. Results show that timescale selection has a determinant impact on the total temporal complementarity.
\end{abstract}

\section{Introduction}

An increase in global awareness regarding environmental problems and climate change, as well as the constant growth of energy demands all over the world, have facilitated the increase in recent decades of the fraction of renewable energies in the power grids and isolated systems in most countries. However, one of the main concerns regarding some of these energy sources is their variability, caused by meteorological factors and usually high and unpredictable fluctuation of the resources, which frequently poses a challenge for its integration into national power grids [1]. This unpredictable nature and dependence on weather conditions and climatic changes constitutes one of the main drawbacks of stand-alone systems based on a variable renewable energy sources (VRES), like wind or solar power, because it may result in performance issues, or in the costly oversizing of the system [2].

One of the most feasible options to overcome (partially or completely) this shortcoming, is to integrate two or more VRES in a combination in which these sources complement each other. This is usually referred to as energetic complementarity and is often expressed in terms of correlation coefficient or a complementarity index. A complementarity index can be defined as a term used to describe the potential of energy sources to complement each other on a 
temporal, spatial or spatiotemporal scale, thereby ensuring supply reliability and minimising power output fluctuations or shortages. When compared to systems based on a single renewable source, hybrid renewable en- ergy systems based on the complementarity between two or more VRES are more likely to improve efficiency and reliability of the system, whilst reducing energy storage requirements.

For the reasons aforementioned, an appropriate evaluation of the variability of the available renewable sources and the synergies between them is crucial for a better technical and financial planning, for increasing the integration capacity and maximising social and economic benefits [3].

\subsection{A literature review about energetic complementarity}

Over the last years, many researchers across the world have conducted investigations related to energetic complementarity between VRES. To provide some context to the method described in this paper, the next paragraphs present a brief review of several recent and relevant works about energetic complementarity.

Gburčik et al. [4] presented an analysis of solar and wind energy resources in Serbia, demonstrating that the fluctuation effects of those resources can be reduced by means of energy storage and complementary use of both sources. These authors analysed the concept of complementarity from both a spatial and a temporal perspective; however, their approach did not apply any universal measure/index. The study conducted by Li et al. [5] investigated not only the temporal complementarity of wind and solar resources (based on correlation coefficient) in a coastal region of Australia, but also assessed if the availability of those resources matched the load demand, concluding that combined operation was enough to supply peak load. A paper by Stoyanov et al. [6] investigated the variations and fluctuations of solar and wind energy source in eight locations in Bulgaria and compared it to the temporal electric load distribution in order to observe if production was able to match power consumption. Hoicka and Rowlands [7] analysed the solar and wind resources complementarity in Ontario, Canada. From their results they concluded that the combination of solar and wind smoothens the power production curve, when compared to production from a single source.

Brazil is one of the countries with most studies related to energetic complementarity. Beluco et al. [8], presented a method to analyse the impact of energetic complementarity on the performance of hybrid solar-hydro power stations, with a follow-up study assessing several different configurations and re sources availability [9]. The research by De Jong et al. [10] investigated the complementarity between solar, wind and hydro resources in the northeast of Brazil, and their combined capacity to supply peak loads. In their analysis, these authors used the Pearson correlation coefficient as a complementarity indicator, and their findings indicate that wind energy has a significant potential to reduce the operation of hydropower during the irrigation period. Ramos et al. [11] proposed a model for assessing wind and hydropower complementarity and its effect on the financial performance and risk exposures, using as case study 10 locations spread over the country. Silva et al. [12] analysed the complementarity of Brazilian hydropower with the offshore wind, by means of comparing monthly precipitation and wind data, whereas Schmidt et al. [13] presented a simulation model for optimising the mix and operation of solar, wind and hydropower generation in a low-carbon Brazilian power system, utilising the underlying assumption of resources complementarity. Cantão et al. [14] proposed so-called correlation maps to evaluate the hydro-wind complementarity for the entire Brazilian territory, based on Pearson and Spearman's rank coefficients, which were also used by Denault et al. [15]. The study by Pianezzola et al. [16], based on the method proposed by Beluco et al. [17] , created spatiotemporal complementarity maps for solar and wind resources for the state of Rio Grande do Sul, in southern Brazil. Rosa et al. [18] used the Pearson correlation coefficient for assessing the complementarity between pairs of hydropower plants, photovoltaic (PV) stations and wind farms in Rio de Janeiro. The Pearson correlation coefficient was also used by Bagatini et al. [19], for assessing complementarity between hydro, wind and solar energy in Rio Grande do Sul (Brazil), and their approach was also based on comparing individual pairs of resources. Recently, Risso et al. [20], suggested a concept of complementarity roses to assess the spatial complementarity between renewable resources and express this feature as maps.

In other complementarity studies around the world, Monforti et al. [21], used a Monte Carlo approach to assess the complementarity of solar and wind resources in Italy, obtaining relatively high monthly correlation coefficients. Kunwar [22] assessed the potential of wind and solar complementarity for compensating the reduced hydropower potential during dry seasons with low stream flow in rivers used for power generation. Francois et al. [23] conducted a complementarity analysis for solar and hydropower resources at northern Italy, considering different temporal scales and using energy balance and storage requirements as indicators. An interesting approach for increasing complementarity between small hydropower stations and solar PV systems was presented by Kougias et al. [24]. Their method is based on the suboptimal orientation of PV panels, which sacrifices PV generation, but increases complementarity.

Solomon et al. [25] used load and VRES data from California, for investigating the beneficial impact of solar and wind resources temporal complementarity on the storage requirements and resulting reliability of the power system. François et al. [26] analysed the solar/hydro complementarity considering the effect of hydrological uncertainty in ungauged 
watersheds, evaluating the method using data from mountain basins in the Eastern Italian Alps. Jurasz et al. [27] used Pearson correlation coefficient to assess the complementarity between solar, wind and hydrokinetic energies in several locations in Poland.

$\mathrm{Xu}$ et al. [28] analysed and mapped the spatiotemporal variations of complementary solar and wind resources over the entire Chinese territory, using the Kendall's rank correlation coefficient as regionalisation indicator. Gulagi et al. [29] investigate how a combination of solar-wind complementarity, storage and transmission can be used to mitigate the monsoon effects in India. Prasad et al. [30] analysed the effect of spatial and temporal synergy between solar and wind resources in Australia, and presented a method that can be readily applied in other parts of the world to investigate synergies between these two VRES. During Filho et al. [31] analysed how temporal complementarity affects storage requirements in solar-hydro hybrid systems.

Jurasz et al. [32] analysed the complementarity of solar and wind energy over Lower Silesia in Poland. In their follow-up study [33] they presented how complementarity between solar and wind resources, coupled with pumped storage hydropower, can be used from the perspective of guaranteeing power system reliability. Jurasz et al [34] investigated how the theoretical complementarity between solar and wind resources can be used to assess the hybrid system reliability, and the impact of various levels of energy storage on the system's overall performance.

More recently, energetic complementarity has also been employed in the formulation of optimisation problems. Jurasz and Mikulik [35] presented a simple mathematical model for selecting an optimal location for solar and wind parks, aiming to reduce the ramp rates of aggregated solar-wind generation, using data from several locations in Poland, considering VRES complementarity on a temporal and spatial scale. Aza-Gnandji et al. [36] assessed the complementarity between solar and wind energy in Benin Republic. In their study they determined the best geographical locations in terms of complementarity by means of Particle Swarm Optimisation. Zhu et al. [37] proposed an economic dispatch strategy based on multi-scale complementary energy sources. These authors proposed an optimisation model, whose objective function was minimising the required output from thermal plants, using as case study data from a power system in southeast China. Zhu et al. [38] presented a complementary operation for hydro-wind-solar system in Jinsha River. In their paper, the authors evaluated the complementarity of the different paired combinations of VRES and set up an optimisation model whose objective was minimising the hydro- power output. Using as case study the wind, solar and hydro- power resources in the Yalong River basin and their output complementarity, Zhang et al. [39] formulated an optimisation model with the objective of minimising the excess energy from wind farms and photovoltaic installations, whilst maximising the stored energy in cascade hydropower stations. Shaner et al. [40] analysed the impact of geophysical variability of solar and wind resources on the system's reliability, storage requirements and transmission infrastructure, testing different mixes of these two sources. Henao et al. [41] presented an optimisation model to increase the penetration of complementary VRES into the Colombian power grid, aiming at minimising system costs, greenhouse gases emissions and blackout events.

Some authors have investigated energetic complementarity on geographical scales larger than countries. Francois et al. [42] proposed to utilize run-of-river hydro power to increase the share of VRES in the energy mix, using as case study 12 European regions. Krutova et al. [43] analysed the smoothing effect of VRES in the context of a supergrid covering Eurasia and Africa, and their findings suggest that the complementarity between the renewable resources of the region could heavily reduce backup energy requirements. Miglietta et al. [44] assessed the local complementarity of wind and solar resources over Europe from a meteorological perspective, using a time series comprising data from three complete years. Sterl et al. [45], based on a case study from West Africa, proposed a new metric called the stability coefficient, created for assessing the solar-wind synergies and limiting energy storage needs. Complementarity can also be achieved within single renewable resources. This is sometimes referred to as system-friendliness and can include wind turbines suitable for low wind situations [46] or solar PV modules with orientations chosen to resemble the load pattern [47].

Complementarity is generally expressed in terms of correlation coefficients or complementarity indices. In most cases, these metrics are used for measuring complementarity between two VRES. However, a few authors have extended the existing methods in order to assess energetic complementarity between more than two sources. Borba and Brito [48] , extending on the method presented by Beluco et al. [17], proposed a dimensionless index for calculating temporal complementarity between two or more energy resources. A recent and interesting study by Han et al. [49] evaluates the complementarity degree between wind, solar and hydropower by means of comparing the fluctuation difference between their individual and combined power generation capacities.

\subsection{Novelty, objective and structure of the paper}

The previous literature review allows noticing some common features of the research on VRES complementarity: 
- the Pearson correlation coefficient is the most commonly applied metric used for energetic complementarity assessment, although some authors follow different approaches, especially in optimisation models proposed for improving the power system operation based on complementarity;

- complementarity is mostly investigated for a combination of only two renewable sources for a given location;

- the analysis on complementarity is performed in three ways: it is either temporal, spatial or spatiotemporal;

- some authors are aiming at analysing or optimising the balance between VRES power output and load demand besides investigating the resources complementarity;

- the complementarity between resources is mainly used to increase system reliability, to boost the economic operation and to improve dispatching strategies;

- the existing approaches for calculating complementarity indices for more than two sources are essentially unidimensional. Thus, information regarding complementarity between a specific paired combination of resources becomes unavailable to the reader in such methods, but on the other hand, correlation coefficient tables do not directly provide information about the total complementarity between the set of resources.

Within this context, the objective of this paper is to introduce a method that simultaneously assesses partial and total temporal complementarity between three variable energy sources, using a combination of correlation coefficients, Euclidean vectors, compromise programming and normalisation. Some benefits and novelties of this approach are the following:

- The mathematical techniques included in the method are well known and ensure the linearity of the results, facilitating their understanding.

- Correlation coefficients are employed for estimating complementarity between each pair of resources, and the Euclidean vector approach allows a bundle representation.

- Compromise programming and normalisation allows to quantify the total temporal complementarity, ranging from total similarity (worst-case scenario) to a maximum feasible complementarity (best-case scenario).

- By calculating correlation coefficients, compromise programming and normalisation, the method is versatile enough for assessing complementarity between time series, power output, etc. in different timescales.

The rest of the paper has the following structure: Section 2 introduces and describes the method for evaluating energetic complementarity between three VRES by means of correlation coefficients, a vector representation and compromise programming; Section 3 presents and discusses a case study that evalu- ates energetic complementarity between three VRES on three different timescales, using hourly information from a southern Poland region as source data; finally, Section 4 provides a short summary of the paper as well as some concluding remarks and prospective researches derived from this work.

\section{Method}

The method presented in this paper can be used for determining the total temporal complementarity between three variable energy sources, by means of a combination of proven mathematical techniques. The following subsections describe the steps of the method.

\subsection{Correlation between each pair of resources and vector representation}

Correlations are measurements of the degree of dependence between two random variables. The most common type of correlation is the Pearson correlation coefficient $\rho_{x y}$, which is widely used in energetic complementarity studies. For a sample of paired data $\left(x_{1}, y_{1}\right), \ldots,\left(x_{n}, y_{n}\right), \rho_{x y}$ can be calculated as:

$$
\begin{aligned}
\rho_{x y} & =\frac{\operatorname{Cov}(x, y)}{\rho_{x} \rho_{y}} \\
& =\frac{\sum_{i=1}^{n}\left(x_{i}-\bar{x}\right)\left(y_{i}-\bar{y}\right)}{\sqrt{\sum_{i=1}^{n}\left(x_{i}-\bar{x}\right)^{2}} \sqrt{\sum_{i=1}^{n}\left(y_{i}-\bar{y}\right)^{2}}}
\end{aligned}
$$

where $\mathrm{n}$ is the size of the sample, $x_{i}$ and $y_{i}$ are the individual sample points of each variable, $\bar{x}$ and ${ }^{\overline{ }}$ are the averages for each sample, $\sigma_{x}$ and $\sigma_{y}$ are the standard deviations. However, for non-normal multivariate distributions, the Pearson correlation coefficient is not a desirable measure of association [15]. For non-normal multivariate distributions, Spearman's rank correlation coefficient $\rho_{x y}$ is a better alternative for assessing the dependence between two random 


\section{Vector for complementarity between three sources}

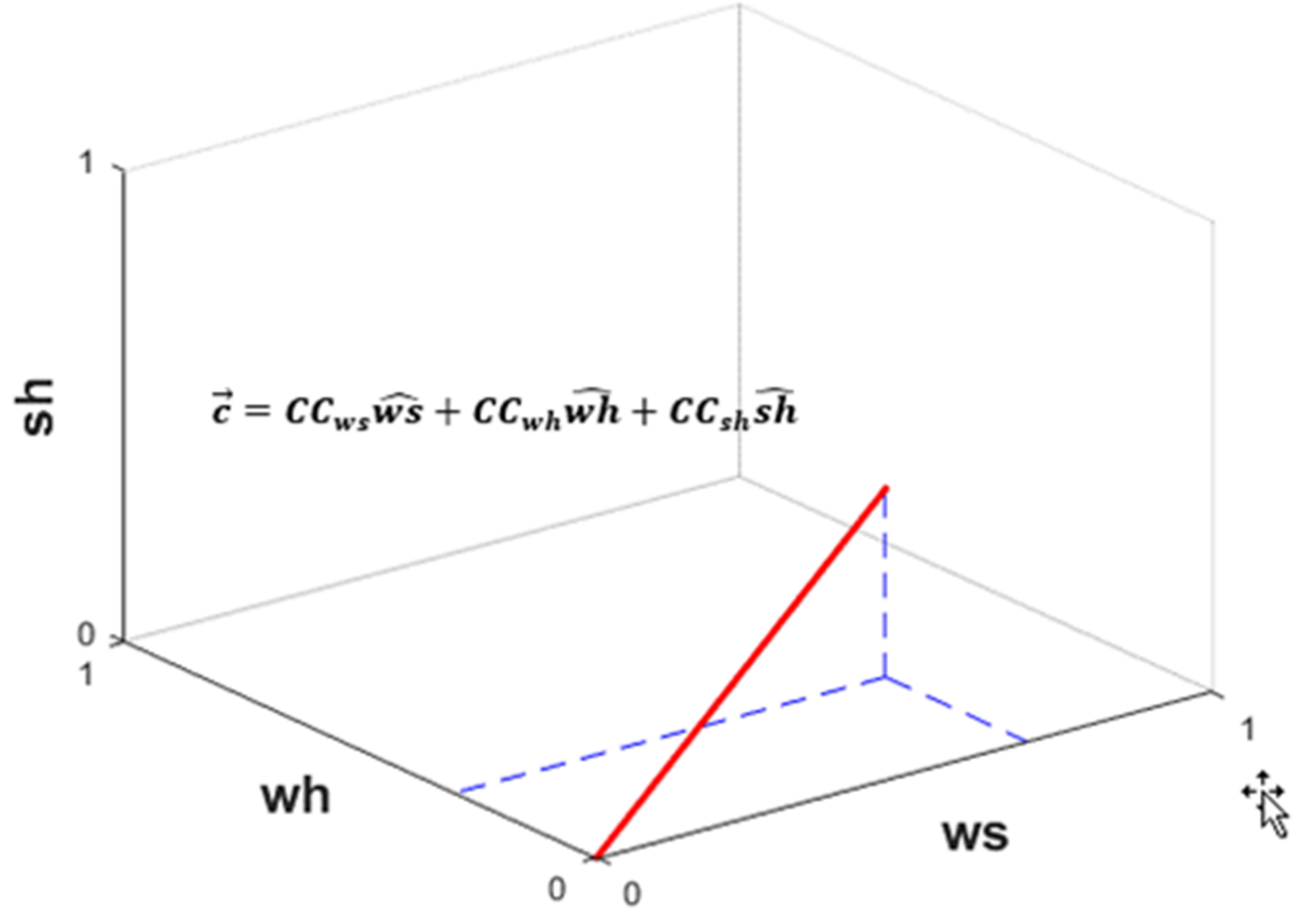

Figure 1: Generic representation of a vector for describing complementarity between three energy sources.

variables, because it removes the relative size of the two variables, and the dependence is measured between the transformed variables [50]. For a sample of size $\mathrm{n}$, the calculation of $\rho_{x y}$ needs the conversion of each $x_{i}$ and $y_{i}$ value to the corresponding rank $x_{i}$, and rank $y_{i}$ :

$$
\rho_{s}(x, y)=\frac{\operatorname{Cov}(\operatorname{rank} \mathrm{x}, \text { rank y })}{\sigma_{\text {rank } \mathrm{x}} \sigma_{\text {rank y }}}
$$

where $\sigma_{\text {rank x }}$ and $\sigma_{\text {rank y }}$ are the standard deviations of the corresponding ranks. The values of these two types of correlation coefficients will always be within the interval $[-1,1]$. Both Pearson and Spearman's coefficients are evaluated in this paper for assessing energetic complementarity. According to Cantão et al. [14], one possible interpretation of correlation coefficient values regarding energetic complementarity is presented in Table 1. A correlation coefficient value close to 0 implies that there's essentially no association between the two variables; a positive value indicates that as the value of one of the variables increases or decreases, the value of the other variable follows a similar behaviour; on the other hand, a negative value means that as the value of one variable increases, the value of the other variable decreases, and vice versa [51]. For this method, each correlation coefficient (CC) found in the previous step becomes one component of a complementarity vector in a multidimensional space, where each dimension is defined by a paired combination of energy sources, and the CC value represents the similarity or complementarity between each pair of resources. For example, let subindices $\mathrm{w}, \mathrm{s}$ and $\mathrm{h}$ represent wind, solar and hydropower resources, correspondingly. These resources allow three possible paired combinations, and the resulting three-dimensional vector c, represent- ing the temporal complementarity between the three energy sources can be specified in the following form:

$$
c=C C_{w s} \hat{w s}+C C_{w h} \hat{w h}+C C_{s h} \overline{s h}
$$

If we considered only one octant of the three-dimensional space of this general example, a generic representation of a complementarity vector is shown in Figure 1. 


\begin{tabular}{cccc}
\hline Behaviour & Correlation coefficient values & Normalisation of correlation coefficient & Interpretation \\
\hline Similarity & $0.9 \leq C C \leq 1.0$ & $0.00 \leq$ Norm. $(\mathrm{CC})<0.05$ & Very strong similarity \\
& $0.6 \leq C C \leq 0.9$ & $0.05 \leq$ Norm. $(\mathrm{CC})<0.20$ & Strong similarity \\
& $0.3 \leq C C \leq 0.6$ & $0.20 \leq$ Norm. (CC) $<0.35$ & Moderate similarity \\
& $0.0 \leq C C \leq 0.3$ & $0.35 \leq$ Norm. $(\mathrm{CC})<0.50$ & Weak similarity \\
\hline Complementarity & $-0.3 \leq C C \leq 0.0$ & $0.50 \leq$ Norm. $(\mathrm{CC})<0.65$ & Weak complementarity \\
& $-0.6 \leq C C \leq 0.3$ & $0.65 \leq$ Norm. (CC) $<0.80$ & Moderate complementarity \\
& $-0.9 \leq C C \leq 0.6$ & $0.80 \leq$ Norm. (CC) $<0.95$ & Strong complementarity \\
& $-1.9 \leq C C \leq 0.9$ & $0.95 \leq$ Norm. (CC) $<1.00$ & Very strong complementarity \\
\hline
\end{tabular}

Table 1: Interpretation of correlation coefficient values (adapted from [14]).

\subsection{Compromise programming}

Compromise programming is a multi-criteria analysis technique that focuses on finding the closest point to the ideal solution, within the domain of the feasible solutions. According to Gershon and Duckstein [52] the metric $L_{p}$ used in compromise programming for estimating the distance of each option $\mathrm{x}$ to the optimal solution (usually unfeasible) can be found by means of the following distance function:

$$
L_{p}(c)=\left[\sum_{k=1}^{n} \alpha_{k}^{p}\left|\frac{f_{k}^{\text {best }}-f_{k}(c)}{f_{k}^{\text {best }}-f_{k}^{\text {worst }}}\right|^{p}\right]^{\frac{1}{p}}
$$

where: $\alpha_{k}^{p}$ are the weights for each component $\mathrm{k}$ (where $\mathrm{k}$ is each paired combination). The method presented in this paper considers that all paired combinations have the same importance, therefore, $\alpha_{k}^{p}=1$ for all cases. Also in equation (3), $f_{k}(c)$ is the $\mathrm{CC}$ value for the corresponding paired combination of resources of vector c; $f_{k}^{\text {best }}$ is the most desirable value of the correlation functions, therefore, $f_{k}^{\text {best }}=-1$, because it would represent full complementarity; $f_{k}^{\text {worst }}$ is the less desirable value of the correlation functions, therefore, $f_{k}^{\text {worst }}=1$, because it would represent full similarity (i.e., the simultaneous occurrence of the resources); $p$ is the parameter that establishes the type of geometrical distance between $f_{k}^{\text {best }}$ and $f_{k}(c)$. As explained by Gershon and Duckstein [52], for $\mathrm{p}=1$, all deviations from $f_{k}^{\text {best }}$ are considered in direct proportion to their magnitudes. For 2 (Euclidean distance) $\leq p<\infty$, the largest deviation has the greatest influence. The present method adopts the value of $\mathrm{p}=1$, allowing a linear assessment of complementarity.

\subsection{Total temporal complementarity index}

It can be easily observed from equation (3) that the corresponding minimum and maximum values of $L_{p}(c)$ are 0 (perfect complementarity for all paired combinations) and $n^{\frac{1}{p}}$ (perfect similarity for all paired combinations). However, for the conditions previously defined and three energy sources, results from heuristics and linear programming indicate that the minimum achievable $\mathrm{Lp}(\mathrm{c}$ ) equals 0.75 (one example is when every correlation coefficient for each paired combination equals -0.5). A proof of this is given in the appendix. Therefore, it is possible to state that a moderate correlation between two VRES does not mean is impossible to achieve a system $100 \%$ based on renewable energy resources, because a third source could fill the deficits of the other two, thus minimising backup power requirements.

A total temporal complementarity index $\kappa_{t}$ can be assessed by normalising the $L_{p}(c)$ metric through the following expression:

$$
\kappa_{t}(c)=\frac{3-L_{p}(c)}{2.25}
$$

with $\kappa_{t}$ values ranging from 0 (perfect similarity) to 1 (perfect complementarity).

\section{Case study and discussion of results}

For a better understanding of the method presented in this paper, this section presents and discusses a case study that evaluates the complementarity between three variable energy sources (wind speed, solar irradiation and stream flow rate - or discharge -) on three different timescales (monthly, daily and hourly). The dataset used in this work corresponds to the hourly measurements of the resources for the 8784 hours of 2008. 


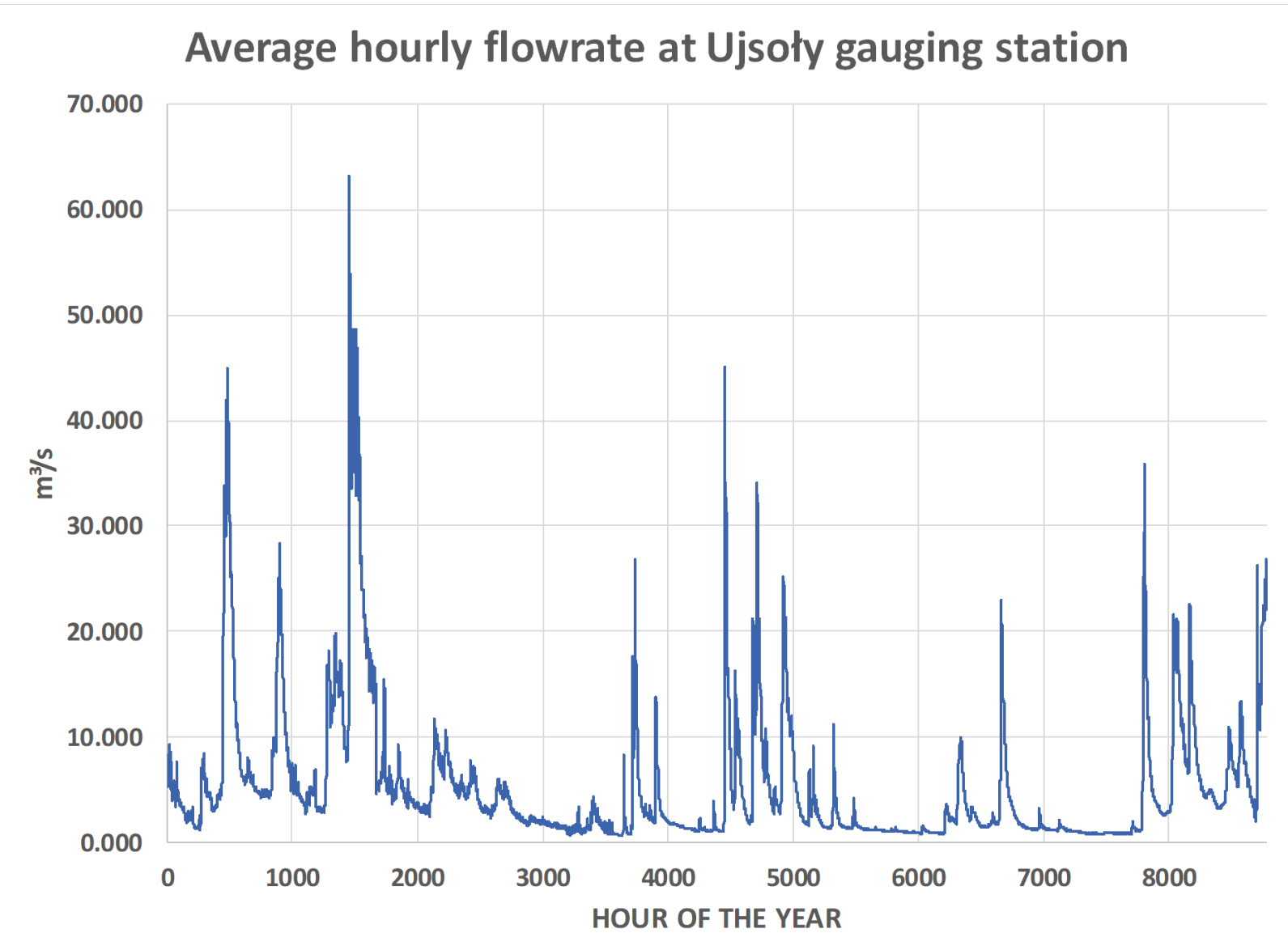

Figure 2: Average hourly flow rate at Ujsoły gauging station for the year 2008.

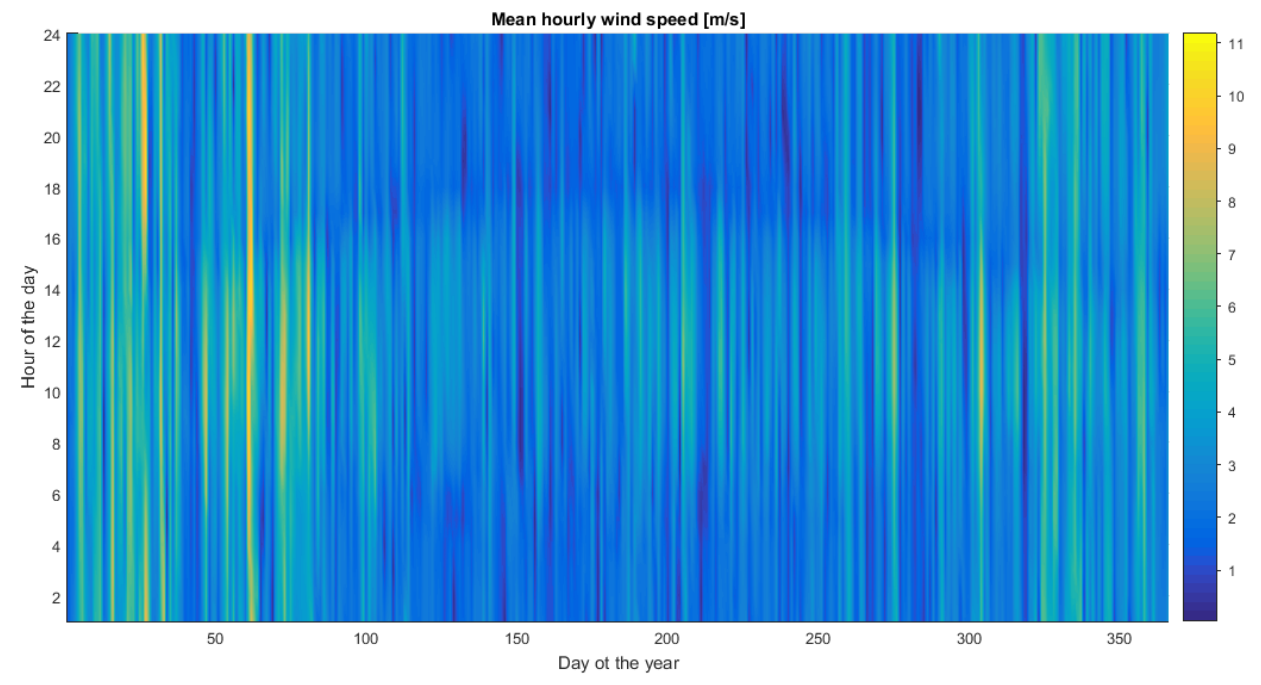

Figure 3: Data map for mean hourly wind speed at the case study area. 


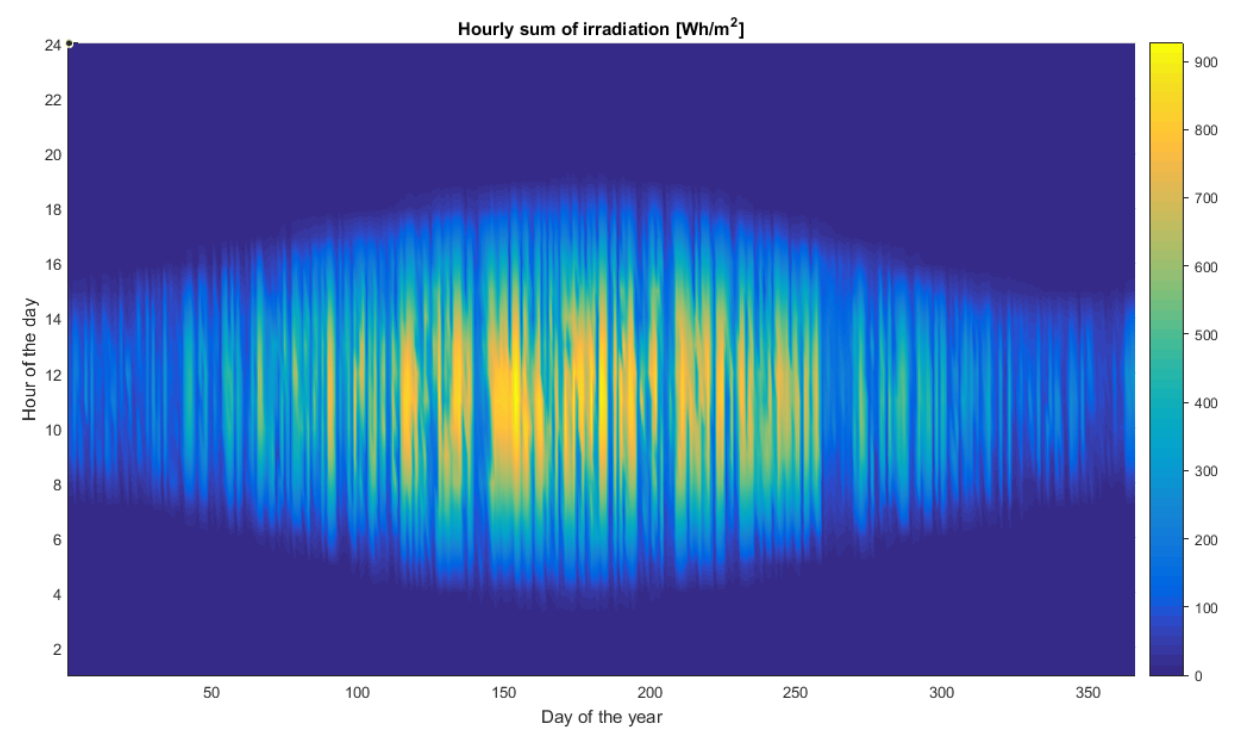

Figure 4: Data map for hourly solar irradiation at the case study area.

\begin{tabular}{|c|c|c|c|c|c|c|c|c|c|c|c|c|}
\hline Month & Jan & Feb & Mar & Apr & May & Jun & Jul & Aug & Sep & Oct & Nov & Dec \\
\hline wind speed $[\mathrm{m} / \mathrm{s}]$ & 4.402 & 3.646 & 3.945 & 2.656 & 2.297 & 2.151 & 2.585 & 2.339 & 2.681 & 2.815 & 3.408 & 3.298 \\
\hline solar irradiation $\left[\frac{\mathrm{kW}}{\mathrm{m}^{2} d}\right]$ & 0.768 & 1.467 & 2.681 & 3.825 & 5.077 & 5.895 & 4.992 & 4.779 & 3.027 & 1.952 & 0.984 & 0.712 \\
\hline river flow rate $\left[\frac{m^{3}}{s}\right]$ & 7.911 & 8.619 & 12.454 & 4.491 & 1.625 & 2.911 & 8.000 & 1.897 & 2.104 & 2.501 & 3.212 & 8.936 \\
\hline \multicolumn{13}{|c|}{ Pearson correlation coefficient $-\rho_{x y}$} \\
\hline \multirow{2}{*}{\multicolumn{6}{|c|}{$\begin{array}{l}\text { Complementarity vector } \\
\text { Compromise programming }\end{array}$}} & \multirow{2}{*}{\multicolumn{7}{|c|}{$-0.815 w s+0.717 w h-0.410 \mathrm{sh}$}} \\
\hline & & & & & & \multirow{2}{*}{\multicolumn{7}{|c|}{$\begin{array}{c}1.246 \\
77.96 \%\end{array}$}} \\
\hline \multicolumn{6}{|c|}{ Total temporal complementarity index $-\kappa_{t}$} & & & & & & & \\
\hline \multicolumn{13}{|c|}{ Spearman's rank correlation coefficient - $\rho_{s}$} \\
\hline \multicolumn{6}{|c|}{ Complementarity vector } & \multicolumn{7}{|c|}{$-0.867 \mathrm{ws}+0.650 \mathrm{wh}-0.517 \mathrm{sh}$} \\
\hline \multicolumn{6}{|c|}{ Compromise programming } & \multirow{2}{*}{\multicolumn{7}{|c|}{1.133}} \\
\hline \multicolumn{6}{|c|}{ Total temporal complementarity index $-\kappa_{t}$} & & & & & & & $82.98 \%$ \\
\hline
\end{tabular}

Table 2: Data and complementarity results on a monthly scale for the case study.

\subsection{Input data}

The study area is situated in southern Poland, within the Soła river basin. At the end of its $89 \mathrm{~km}$ course, the Soła river has a mean discharge of $19.3 \frac{\mathrm{m}^{3}}{\mathrm{~s}}$, and a watershed covering approximately $1391 \mathrm{~km}^{2}$ [53]. For our case study, the stream flow data corresponds to the discharge measured at the Ujsoły gauging station, located at coordinates $49^{\circ} 29^{\prime} 33^{\prime \prime} \mathrm{N} 19^{\circ} 07^{\prime} 01$ "E, in a region mainly covered by forests and agropastoral farming. The discharge time series for the Soła river at the Ujsoły gauging station was obtained from the site of the Polish Institute of Meteorology and Water Management - National Research Institute (IMGW-PIB) at: https://danepubliczne.imgw.pl. The hydrograph corresponding to the average hourly flow rate for 2008 is shown in Figure 2.

Wind speed and solar irradiation time series for this area correspond to satellite measurements [54, 55] . It is worth noticing that previous studies in the area have demonstrated a good fit between this records and ground data [32]. The data maps describing the behaviour of these two resources along the 8784 hours of 2008 are shown in Figure 3 (wind speed) and Figure 4 (solar irradiation).

\subsection{Results and discussion}

To illustrate the method presented in this paper, the three renewable resources available at the study area are evaluated on three different timescales to assess energetic complementarity. As in the method explanation, the indices for identifying each resource are: $\mathrm{w}$ for wind, $\mathrm{h}$ for hydro and s for solar. For assessing monthly complementarity between the three 


\section{Pearson correlation coefficient $-\rho_{x y}$}

Complementarity vector

Compromise programming

Total temporal complementarity index $-\kappa_{t}$

Spearman's rank correlation coefficient $-\rho_{s}$

Complementarity vector

Compromise programming

Total temporal complementarity index $-\kappa_{t}$
$-0.441 \mathrm{ws}+0.360 \mathrm{wh}-0.287 \mathrm{sh}$

1.316

$74.80 \%$

Table 3: Complementarity results on a daily scale for the case study.

\begin{tabular}{cc}
\hline \multicolumn{2}{c}{ Pearson correlation coefficient $-\rho_{x y}$} \\
\hline Complementarity vector & $-0.017 \mathrm{ws}+0.294 \mathrm{wh}-0.132 \mathrm{sh}$ \\
Compromise programming & 1.573 \\
Total temporal complementarity index $-\kappa_{t}$ & $63.40 \%$ \\
\hline Spearman's rank correlation coefficient $-\rho_{s}$ \\
\hline Complementarity vector & $+0.048 \mathrm{ws}+0.244 \mathrm{wh}-0.118 \mathrm{sh}$ \\
Compromise programming & 1.587 \\
Total temporal complementarity index $-\kappa_{t}$ & $62.80 \%$ \\
\hline
\end{tabular}

Table 4: Complementarity results on an hourly scale for the case study.

\section{Contribution of each paired combination to the total complementarity} Timescale : Month

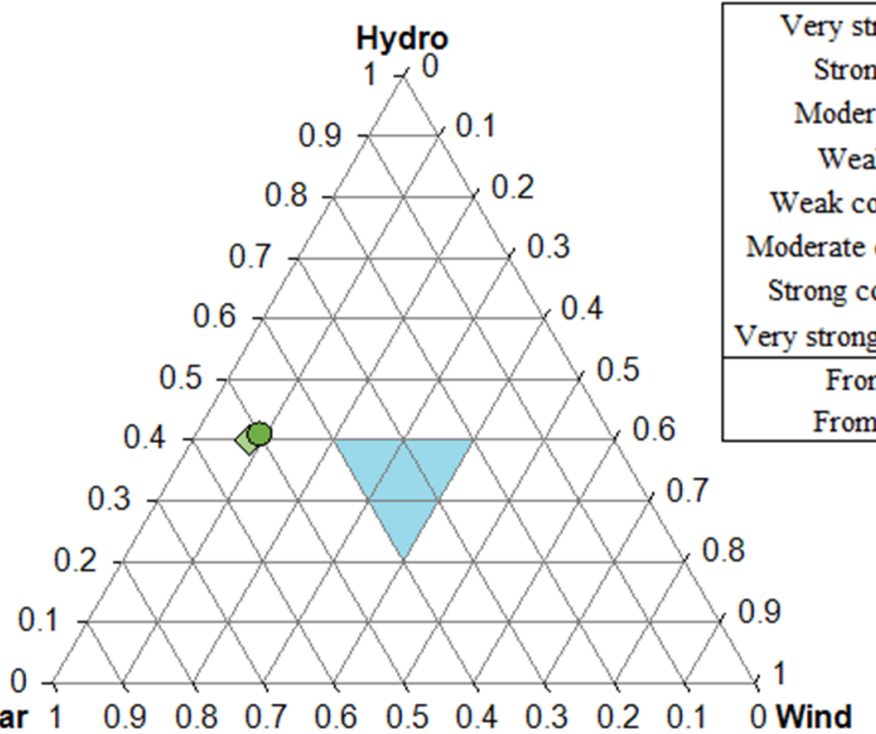

Figure 5: Contribution of each paired combination of VRES to $\kappa_{t}$ on a monthly scale. 


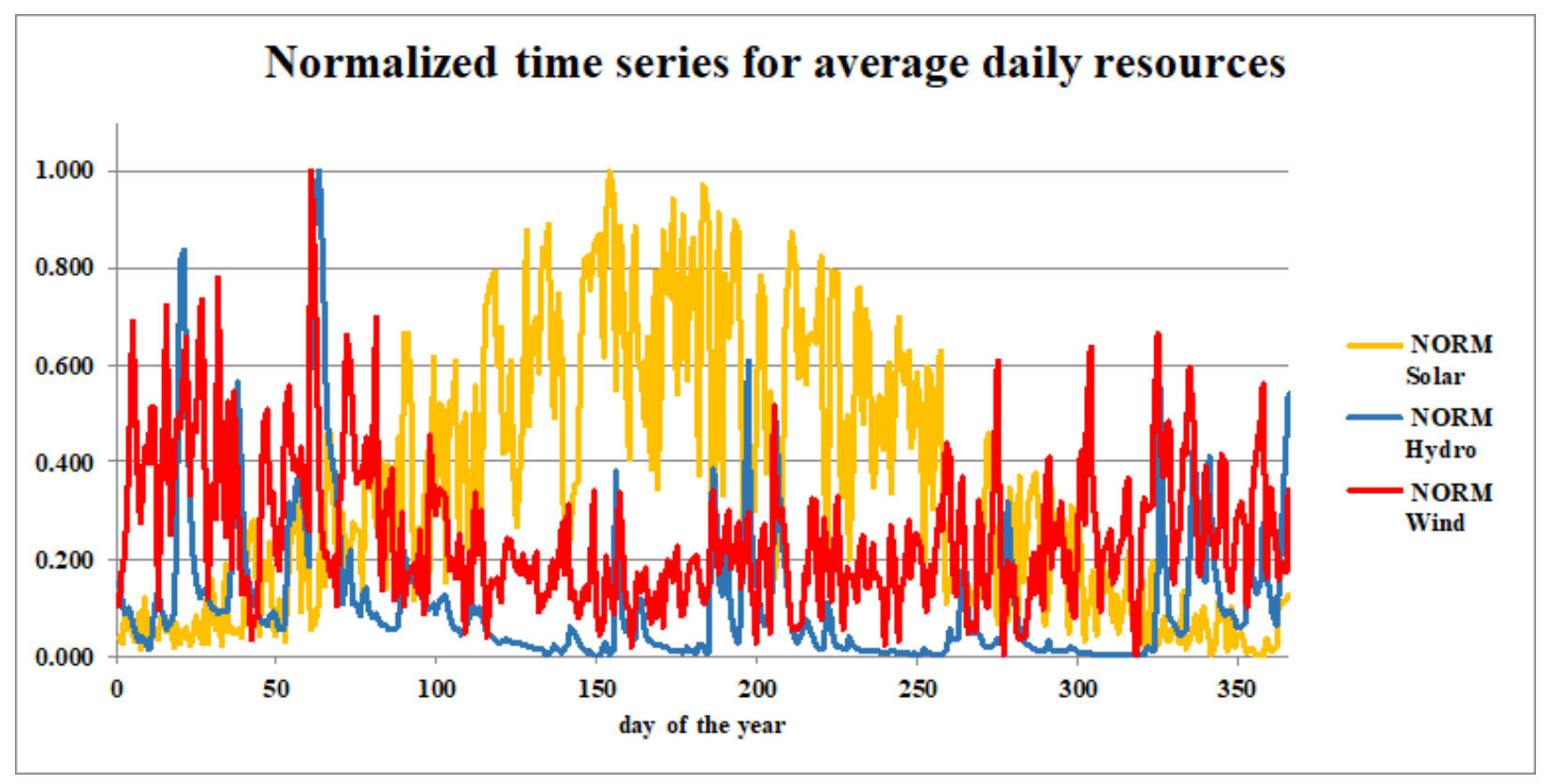

Figure 6: Normalized time series for average daily resources.

\section{Contribution of each paired combination to the total complementarity} Timescale : Day

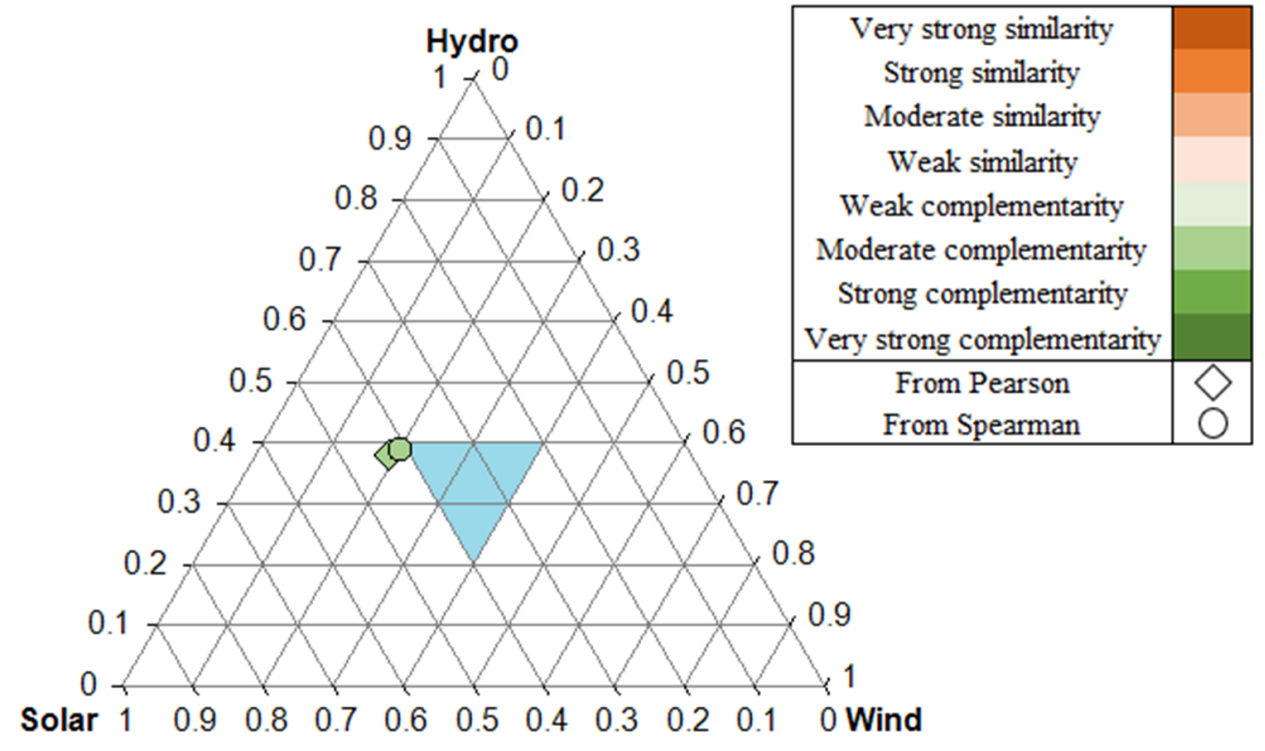

Figure 7: Contribution of each paired combination of VRES to $\kappa_{t}$ on a daily scale. 


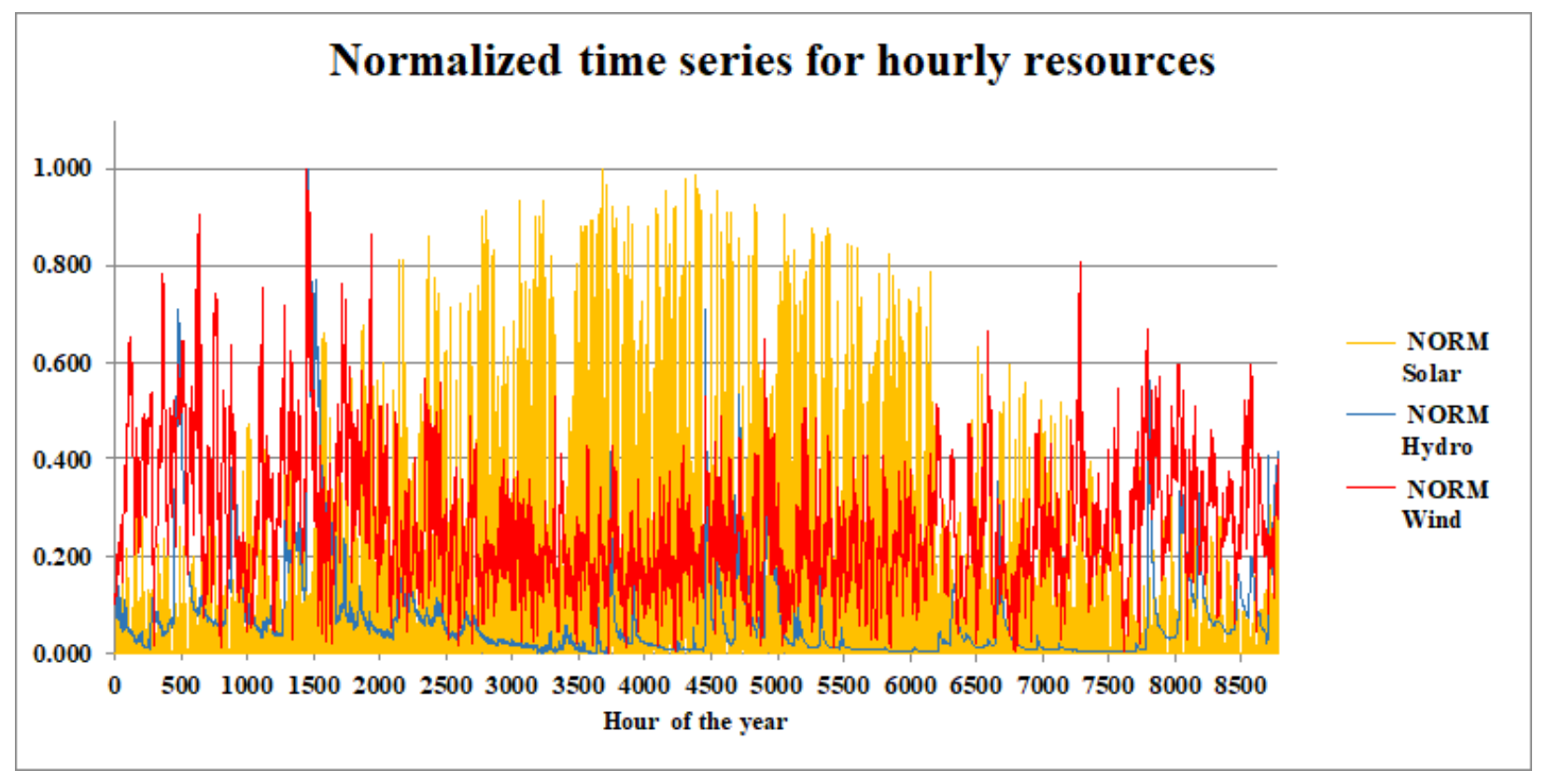

Figure 8: Normalized time series for hourly resources.

\section{Contribution of each paired combination to the total complementarity Timescale : Hour}

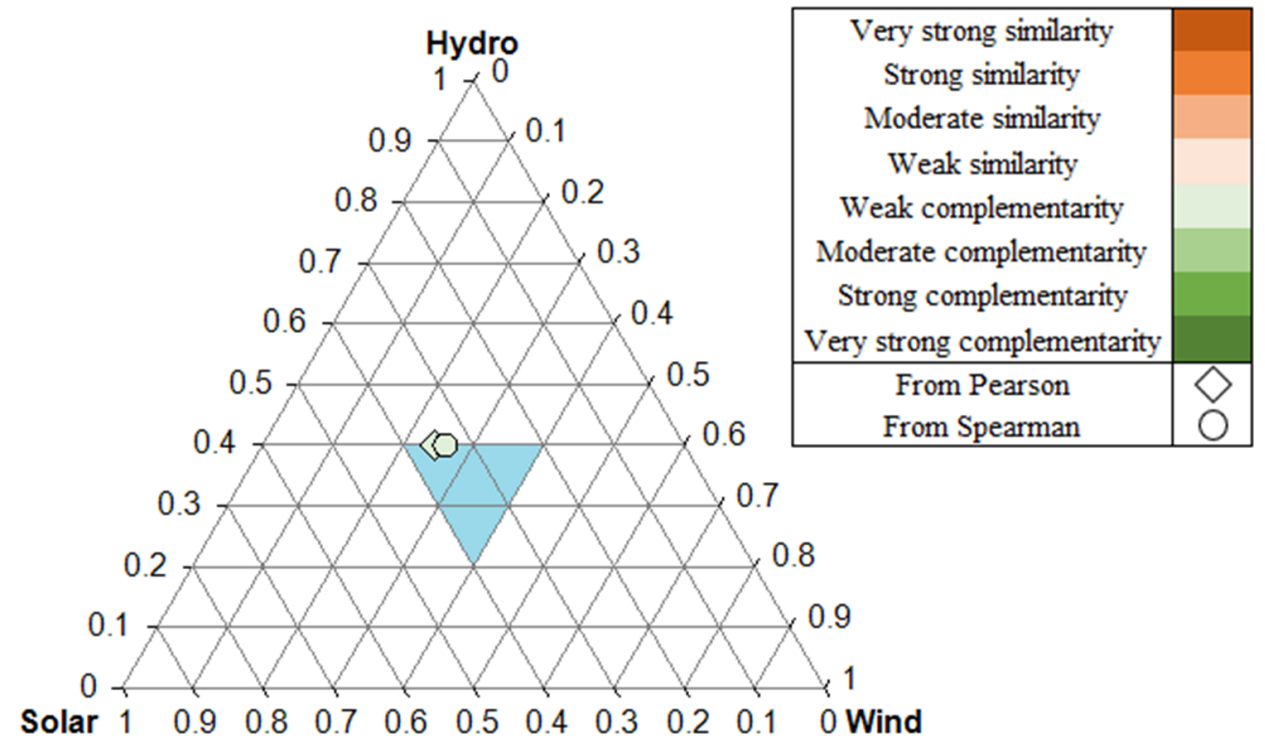

Figure 9: Contribution of each paired combination of VRES to $\kappa_{t}$ on a hourly scale. 
sources, there were calculated the average hourly wind speed and mean flow rate, as well as the mean daily sum of solar irradiation. Table 2 details the case study data and results for energetic complementarity, considering a monthly timescale. These results show that on a monthly scale, the complementarity between wind and solar resources is the highest among the three paired combinations, indicating that months with a lower average solar irradiation are usually the ones with a higher average windspeed, and vice versa. This is in line with the findings presented by Jurasz et al. [34]. Similarly, the paired combination with the lowest complementarity (it presents a strong similarity), corresponds to the combination of wind and hydro resources $\left(\rho_{x y}=+0.717-\rho_{s}=+0.650\right)$, implying that both resources follow similar patterns (in terms of their lower and higher values) along the year.

For the case study data, the application of the proposed method results in a total monthly complementarity index $\kappa_{t}$ equal to 0.780 when considering Pearson Correlation Coefficient, and 0.830 for Spearman's Rank. Therefore, and based on Table 1, the joint behaviour between the three energy sources on a monthly scale suggest a moderate to strong bundle complementarity. The ternary plot in Figure 5 displays the contribution of each paired combination to $\kappa_{t}$, based on the normalisation of the individual distances calculated by means of equation 3. Using as illustrative example the results shown in the Figure 5, and based on $\rho_{s}$, it is observed that wind-solar accounts for 50\% of $\kappa_{t}$, whilst solar-hydro and wind-hydro contribute with $41 \%$ and $9 \%$, correspondingly. The coloured triangle in the centre of the chart is the area where balanced distributions in terms of contribution to $\kappa_{t}$, would be plotted (for example, a perfectly distributed contribution of the three VRES would be in the exact centre of the plot).

The Figure 6 displays the normalized time series for the average daily resources. From this graph it is easily observed that some complementarity exists between wind and solar, whilst wind and hydro resources exhibit some similarity in their time series on a daily scale. These observations are supported by the results presented in Table 3, which shows that individual complementarities range from weak to moderate complementarity or similarity.

Nevertheless, for this timescale, the results for $\kappa_{t}$ implies that a hybrid power system might yield better results by considering a combination of these three resources, instead of a combination of just two of them, which would probably require a significant amount of backup power or energy storage. The ternary plot in Figure 7 displays the contribution of each paired combination to $\kappa_{t}$, and it can be mentioned that solar-hydro and solar-wind resources have a similar impact on the value of $\kappa_{t}$, suggesting that any hybrid system planning and operation based on a daily scale should considered solar as the main energy source.

The normalized time series for the hourly resources is shown in Figure 8, and the complementarity results are presented in Table 4. As expected, wind-solar complementarity is heavily affected by the diurnal cycle, as was also shown by Jurasz et al. [34], so much that the linear relationship between these two resources is almost inexistent (Pearson presents a weak complementarity, whilst Spearman's rank correlation results in a weak similarity). The correlation coefficients also evinced weak similarity (wind-hydro) and weak complementarity (solar- hydro) for the other paired combinations. For the bundle of the three sources, the total temporal complementarity in an hourly scale results in a $\kappa_{t}$ value of around $60 \%$ of the maximum achievable, denoting an overall weak complementarity according to Table 1 . The contribution of each paired combination to $\kappa_{t}$ is shown in Figure 9.

Based on the previous observations, some advantages of the method become clear by comparing the results for complementarity between the three sources on each timescale. One of them relates to its potential as a tool for preliminary assessment of power generation planning and scheduling. The optimal scheduling of systems that include a large renewables fraction heavily depends on the forecasting accuracy of the correspond- ing resources, which is in turn directly associated with the time-scale used for scheduling.

The method presented in this paper allows not only to assess the total complementarity between the three sources, but also to evaluate the complementarity between each paired combination of resources. Based on the results of the case study, a system whose operation is based on a month-ahead scheduling might be more effective by prioritising wind turbines and photovoltaic panels along with their corresponding energy storage devices. Similarly, a system in this region whose operation is based on a short-time or real time scheduling would probably have a better performance by relying on a combination of the three VRES under consideration. Correlation coefficients, compromise programming and normalisation are three proven mathematical methods, which combined in the proposed method provide an interesting tool for comparing different energy sources with different units of measurement. Another advantage of this process is that it makes the process versatile, because it admits useful modifications. For example, instead of assessing the resources complementarity, the complementarity could be assessed in terms of power outputs by considering available head and efficiency (for hydropower), temperature and PV panel characteristics (for solar power) and wind turbine specifications (for wind power). Other variations could include capacity factors, blackout probability, etc. Another advantage of the method is that all results are on a linear scale, providing a direct interpretation. Hybrid power systems set in areas with a low total temporal complementarity index $\kappa_{t}$, would benefit from hydropower reservoirs or other energy storage devices to improve their performance and reliability, whilst also avoiding the oversizing of the system. 


\section{Conclusions}

This paper presented a method for assessing energetic complementarity between three energy sources by means of a combination of correlation coefficients, compromise programming and normalisation. This approach allows the simultaneous evaluation of partial and total complementarity. The correlation coefficients allow measuring the complementarity of each paired combination of resources, whilst normalisation of compromise programming results accounts for the total complementarity. The method can be used in the design stages of autonomous hybrid power systems.

The case study results indicate that timescale selection has a direct impact on the value of the vector components (and hence on total complementarity). Therefore, this dependence must be taken into consideration when using energetic complementarity indices for power generation planning and scheduling purposes.

Correlation coefficients make possible the comparison of different energy resources with different units of measurement. In addition, the method allows practical modifications to assess other complementarity features like power output, capacity factors, etc. The linear scale and straightforward interpretation of the results is another benefit of using the approach proposed in this paper.

Based on the findings of this study and the previous paragraphs, future research might extend in the following directions:

- Employing the method to assess spatial and spatiotemporal energetic complementarity. This could also include the appraisal of complementarity between existing VRES plants.

- Using the complementarity index $\kappa_{t}$ as a parameter or as part of the objective function in an optimisation model, aiming to define the best energy mix, improving reliability of the system or determining the optimal operation schedule.

- Including more than three variables energy sources and evaluate the impact on energy storage and capacity factors.

\section{Acknowledgements}

The authors are grateful for the support received by their institutions for the research work that resulted in this paper. The third author acknowledges the financial support received from CNPq for his research work (proc. n.312941/2017-0).

\section{References}

[1] Bo Ming, Pan Liu, Shenglian Guo, Xiaoqi Zhang, Maoyuan Feng, and Xianxun Wang. Optimizing utility-scale photovoltaic power generation for integration into a hydropower reservoir by incorporating long-and short-term operational decisions. Applied Energy, 204:432-445, 2017.

[2] Hossein Safaei and David W Keith. How much bulk energy storage is needed to decarbonize electricity? Energy \& Environmental Science, 8(12):3409-3417, 2015.

[3] Hengxu Zhang, Yongji Cao, Yi Zhang, and Vladimir Terzija. Quantitative synergy assessment of regional wind-solar energy resources based on merra reanalysis data. Applied energy, 216:172-182, 2018.

[4] Petar Gburčik, Verica Gburčik, Milivoj Gavrilov, Vladimir Srdanović, and Sreten Mastilović. Complementary regimes of solar and wind energy in serbia. Geographica Pannonica, (10):22-25, 2006.

[5] Yi Li, Vassilios G Agelidis, and Yash Shrivastava. Wind-solar resource complementarity and its combined correlation with electricity load demand. In 2009 4th IEEE conference on Industrial electronics and applications, pages 3623-3628. IEEE, 2009.

[6] V. Lazarov L. Stoyanov, G. Notton and M. Ezzat. Wind and solar energies production complementarity for various bulgarian sites. page 311-325, 2010.

[7] Christina E Hoicka and Ian H Rowlands. Solar and wind resource complementarity: Advancing options for renewable electricity integration in ontario, canada. Renewable Energy, 36(1):97-107, 2011.

[8] Alexandre Beluco, Paulo Kroeff de Souza, and Arno Krenzinger. A method to evaluate the effect of complementarity in time between hydro and solar energy on the performance of hybrid hydro pv generating plants. Renewable Energy, 45:24-30, 2012.

[9] A Beluco, PK Souza, and A Krenzinger. Influence of different degrees of complementarity of solar and hydro energy availability on the performance of hybrid hydro pv generating plants. energy and power engineering, 5 , 332-342, 2013. 
[10] P De Jong, AS Sánchez, K Esquerre, Ricardo de Araújo Kalid, and Ednildo Andrade Torres. Solar and wind energy production in relation to the electricity load curve and hydroelectricity in the northeast region of brazil. Renewable and Sustainable Energy Reviews, 23:526-535, 2013.

[11] DS Ramos, LAS Camargo, E Guarnier, and LT Witzler. Minimizing market risk by trading hydro-wind portfolio: a complementarity approach. In 2013 10th International Conference on the European Energy Market (EEM), pages 1-8. IEEE, 2013.

[12] Allan Rodrigues Silva, Felipe Mendonca Pimenta, Arcilan Trevenzoli Assireu, and Maria Helena Constantino Spyrides. Complementarity of brazils hydro and offshore wind power. Renewable and Sustainable Energy Reviews, 56:413-427, 2016.

[13] Johannes Schmidt, Rafael Cancella, and Amaro O Pereira Jr. An optimal mix of solar pv, wind and hydro power for a low-carbon electricity supply in brazil. Renewable Energy, 85:137-147, 2016.

[14] Mauricio P Cantão, Marcelo R Bessa, Renê Bettega, Daniel HM Detzel, and João M Lima. Evaluation of hydrowind complementarity in the brazilian territory by means of correlation maps. Renewable Energy, 101:1215-1225, 2017.

[15] Michel Denault, Debbie Dupuis, and Sébastien Couture-Cardinal. Complementarity of hydro and wind power: Improving the risk profile of energy inflows. Energy Policy, 37(12):5376-5384, 2009.

[16] Gilberto Pianezzola, Arno Krenzinger, and Fausto Alfredo Canales Vega. Complementarity maps of wind and solar energy resources for rio grande do sul, brazil. Energy and power engineering [recurso eletrônico].[Wuhan, China]. Vol. 9, no. 9 (2017), p. 489-504, 2017.

[17] Alexandre Beluco, Paulo Kroeff de Souza, and Arno Krenzinger. A dimensionless index evaluating the time complementarity between solar and hydraulic energies. Renewable Energy, 33(10):2157-2165, 2008.

[18] Caroline de Oliveira Costa Souza Rosa, Kelly Costa, Eliane da Silva Christo, and Pâmela Braga Bertahone. Complementarity of hydro, photovoltaic, and wind power in rio de janeiro state. Sustainability, 9(7):1130, 2017.

[19] Marcos Bagatini, Mariana G Benevit, Alexandre Beluco, and Alfonso Risso. Complementarity in time between hydro, wind and solar energy resources in the state of rio grande do sul, in southern brazil. Energy and Power Engineering, 9(09):515, 2017.

[20] Alfonso Risso, Alexandre Beluco, and Rita Marques Alves. Complementarity roses evaluating spatial complementarity in time between energy resources. Energies, 11(7):1918, 2018.

[21] F Monforti, T Huld, K Bódis, L Vitali, M D'isidoro, and R Lacal-Arántegui. Assessing complementarity of wind and solar resources for energy production in italy. a monte carlo approach. Renewable Energy, 63:576-586, 2014.

[22] Surendra B Kunwar. Complementarity of wind, solar and hydro resources for combating seasonal power shortage in nepal. In World Sustainability Forum, 2014.

[23] Baptiste Francois, Marco Borga, Jean-Dominique Creutin, Benoit Hingray, Damien Raynaud, and Julian-Friedrich Sauterleute. Complementarity between solar and hydro power: Sensitivity study to climate characteristics in northern-italy. Renewable energy, 86:543-553, 2016.

[24] Ioannis Kougias, Sándor Szabó, Fabio Monforti-Ferrario, Thomas Huld, and Katalin Bódis. A methodology for optimization of the complementarity between small-hydropower plants and solar pv systems. Renewable Energy, 87:1023-1030, 2016.

[25] AA Solomon, Daniel M Kammen, and D Callaway. Investigating the impact of wind-solar complementarities on energy storage requirement and the corresponding supply reliability criteria. Applied energy, 168:130-145, 2016.

[26] B François, D Zoccatelli, and M Borga. Assessing small hydro/solar power complementarity in ungauged mountainous areas: A crash test study for hydrological prediction methods. Energy, 127:716-729, 2017.

[27] Jakub Jurasz, Adam Piasecki, and Marcin Wdowikowski. Assessing temporal complementarity of solar, wind and hydrokinetic energy. In E3S web of conferences, volume 10, page 00032. EDP Sciences, 2016.

[28] Lanjing Xu, Zhiwei Wang, and Yanfeng Liu. The spatial and temporal variation features of wind-sun complementarity in china. Energy Conversion and Management, 154:138-148, 2017.

[29] Ashish Gulagi, Manish Ram, and Christian Breyer. Solar-wind complementarity with optimal storage and transmission in mitigating the monsoon effect in achieving a fully sustainable electricity system for india. In $1 s t$ International Conference on Large-Scale Grid Integration of Renewable Energy in India, pages 6-8, 2017.

[30] Abhnil A Prasad, Robert A Taylor, and Merlinde Kay. Assessment of solar and wind resource synergy in australia. Applied Energy, 190:354-367, 2017. 
[31] Frederico A During Fo, Alexandre Beluco, Elton G Rossini, and José de Souza. Influence of time complementarity on energy storage through batteries in hydro pv hybrid energy system. Computational Water, Energy, and Environmental Engineering, 7(03):142, 2018.

[32] Jakub Jurasz, Marcin Wdowikowski, Bartosz Kaźmierczak, and Paweł Dąbek. Temporal and spatial complementarity of wind and solar resources in lower silesia (poland). In E3S web of conferences, volume 22, page 00074. EDP Sciences, 2017.

[33] Jakub Jurasz, Paweł B Dąbek, Bartosz Kaźmierczak, Alexander Kies, and Marcin Wdowikowski. Large scale complementary solar and wind energy sources coupled with pumped-storage hydroelectricity for lower silesia (poland). Energy, 161:183-192, 2018.

[34] Jakub Jurasz, Alexandre Beluco, and Fausto A Canales. The impact of complementarity on power supply reliability of small scale hybrid energy systems. Energy, 161:737-743, 2018.

[35] Jakub Jurasz and Jerzy Mikulik. Site selection for wind and solar parks based on resources temporal and spatial complementarity-mathematical modelling approach. Przeglad Elektrotechniczny, 93(7):86-91, 2017.

[36] Maurel Aza-Gnandji, François Xavier Fifatin, A Hypolite J Hounnou, Frédéric Dubas, Didier Chamagne, Christophe Espanet, and Antoine Vianou. Complementarity between solar and wind energy potentials in benin republic. In Advanced Engineering Forum, volume 28, pages 128-138. Trans Tech Publ, 2018.

[37] Jizhong Zhu, Xiaofu Xiong, and Peizheng Xuan. Dynamic economic dispatching strategy based on multi-timescale complementarity of various heterogeneous energy. DEStech Transactions on Environment, Energy and Earth Sciences, (appeec), 2018.

[38] Yanmei Zhu, Shijun Chen, Weibin Huang, Li Wang, and Guangwen Ma. Complementary operational research for a hydro-wind-solar hybrid power system on the upper jinsha river. Journal of Renewable and Sustainable Energy, 10(4):043309, 2018.

[39] Xinshuo Zhang, Guangwen Ma, Weibin Huang, Shijun Chen, and Shuai Zhang. Short-term optimal operation of a wind-pv-hydro complementary installation: Yalong river, sichuan province, china. Energies, 11(4):868, 2018.

[40] Matthew R Shaner, Steven J Davis, Nathan S Lewis, and Ken Caldeira. Geophysical constraints on the reliability of solar and wind power in the united states. Energy \& Environmental Science, 11(4):914-925, 2018.

[41] Felipe Henao, Yeny Rodriguez, Juan Pablo Viteri, and Isaac Dyner. Optimising the insertion of renewables in the colombian power sector. Renewable Energy, 132:81-92, 2019.

[42] B François, B Hingray, D Raynaud, M Borga, and JD Creutin. Increasing climate-related-energy penetration by integrating run-of-the river hydropower to wind/solar mix. Renewable Energy, 87:686-696, 2016.

[43] Maria Krutova, Alexander Kies, Bruno U Schyska, and Lueder von Bremen. The smoothing effect for renewable resources in an afro-eurasian power grid. Advances in Science and Research, 14:253-260, 2017.

[44] Mario Marcello Miglietta, Thomas Huld, and Fabio Monforti-Ferrario. Local complementarity of wind and solar energy resources over europe: an assessment study from a meteorological perspective. Journal of Applied Meteorology and Climatology, 56(1):217-234, 2017.

[45] Sebastian Sterl, Stefan Liersch, Hagen Koch, Nicole PM van Lipzig, and Wim Thiery. A new approach for assessing synergies of solar and wind power: implications for west africa. Environmental Research Letters, 13(9):094009, 2018.

[46] Lion Hirth and Simon Müller. System-friendly wind power: How advanced wind turbine design can increase the economic value of electricity generated through wind power. Energy Economics, 56:51-63, 2016.

[47] Kabitri Chattopadhyay, Alexander Kies, Elke Lorenz, Lüder von Bremen, and Detlev Heinemann. The impact of different pv module configurations on storage and additional balancing needs for a fully renewable european power system. Renewable energy, 113:176-189, 2017.

[48] Elizando M Borba and Renato M Brito. An index assessing the energetic complementarity in time between more than two energy resources. Energy and Power Engineering, 9(09):505, 2017.

[49] Shuang Han, Lu-na Zhang, Yong-qian Liu, Hao Zhang, Jie Yan, Li Li, Xiao-hui Lei, and Xu Wang. Quantitative evaluation method for the complementarity of wind-solar-hydro power and optimization of wind-solar ratio. Applied Energy, 236:973-984, 2019.

[50] René Carmona. Statistical analysis of financial data in R, volume 2. Springer, 2014.

[51] Miguel A Vega-Sánchez, Paulina D Castañeda-Jiménez, Rafael Peña-Gallardo, Antonio Ruiz-Alonso, Jorge A Morales-Saldaña, and Elvia R Palacios-Hernández. Evaluation of complementarity of wind and solar energy resources over mexico using an image processing approach. In 2017 IEEE International Autumn Meeting on Power, Electronics and Computing (ROPEC), pages 1-5. IEEE, 2017. 
[52] Mark Gershon and Lucien Duckstein. Multiobjective approaches to river basin planning. Journal of Water Resources Planning and Management, 109(1):13-28, 1983.

[53] Edeltrauda Helios-Rybicka, Agnieszka Hołda, and Elżbieta Jarosz. Monitoring and quality assessment of selected physical and chemical parameters of the sola river system, south poland. Inziynieria Środowiska/Akademia Górniczo-Hutnicza im. S. Staszica w Krakowie, 10:45-58, 2005.

[54] Global modeling and assimilation office (gmao). http://doi.org/10.5067/VJAFPLI1CSIV. Accessed: Oct14, 2018.

[55] Copernicus atmosphere monitoring service products. http://www.soda-pro.com/web-services/radiati on/camsradiation-service. Accessed: 15-Nov-2018.

\section{A Appendix - Minimum compromise programming distance.}

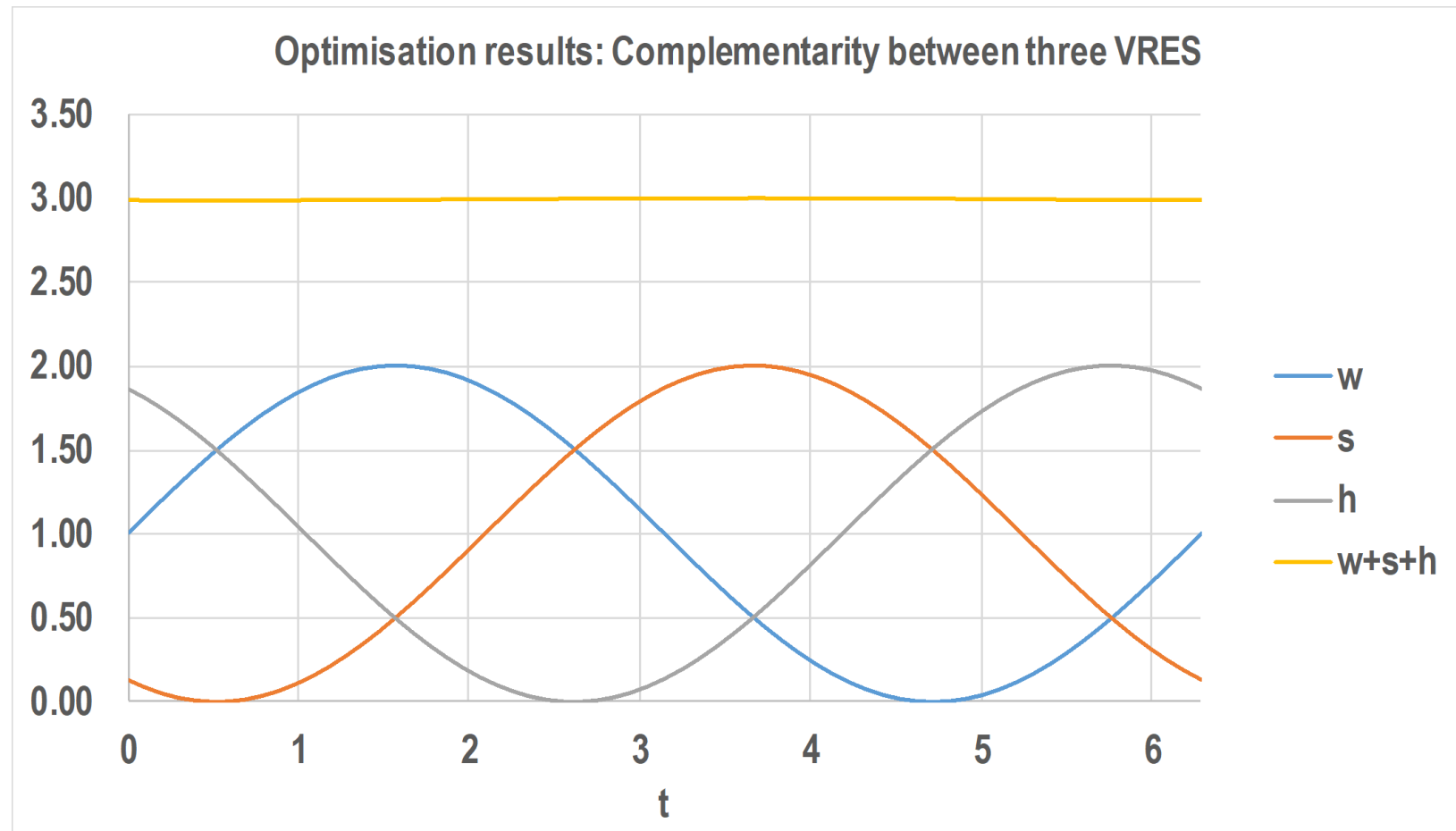

Figure 10: Normalized time series for hourly resources.

Let us consider three idealised time series for $\mathrm{w}$ - wind, $\mathrm{s}$ - solar and $\mathrm{h}$ - hydropower resources, each one of them having a sine function form whose value depends on time $-t$ and phase shift - $\Phi$ :

$$
\begin{aligned}
w(t) & =1+\sin (t) \\
s(t) & =1+\sin (t+\Phi) \\
h(t) & =1+\sin (t+2 \Phi)
\end{aligned}
$$

The three paired combinations allow calculating three possible correlations coefficients - CC (Pearson or Spearman), within the interval $[-1,1]$. We can consider each correlation as part of a three-dimensional vector c:

$$
c(t)=\left(C C_{w s}, C C_{w h}, C C_{s h}\right)
$$

For this system, the optimisation problem can be defined as finding the $\Phi$ value that minimizes the compromise programming distance, or $L_{p}$ metric:

$$
\min L_{p}(c)=\left[\sum_{k=1}^{n} \alpha_{k}^{p}\left|\frac{f_{k}^{\text {best }}-f_{k}(c)}{f_{k}^{\text {best }}-f_{k}^{\text {worst }}}\right|^{p}\right]^{\frac{1}{p}}
$$

with: 
- $\alpha_{k}^{p}=1$ for all cases;

- $p=1$, direct proportion of magnitude

- $f_{k}(c)=C C$ value for paired combination $k$ of vector $c$;

- $f_{k}^{\text {best }}=-1$, representing full complementarity;

- $f_{k}^{\text {worst }}=1$, representing full similarity;

- $0 \leq t, \Phi \leq 2 \pi$.

Satisfying the time interval constraints, it was found that the $\Phi$ value $\left(\frac{2 \pi}{3}\right)$ results in a minimum $L_{p}(c)=0.750$ with $C C=-0.5$ for the three paired combinations. Figure 10 displays the behaviour of the idealised time series when $\Phi=\frac{2 \pi}{3}$. As a general demonstration of this minimum achievable $L_{p}(c)$ value, imagine we have $\mathrm{n}$ random variables $x_{i}$, each with unit variance, as in the case of correlation coefficients $\rho$. Therefore, the sum of the variances:

$$
\begin{aligned}
\operatorname{Var}\left(\sum_{i=1}^{n} x_{i}\right) & =\sum_{i, j=1}^{n} \operatorname{Cov}\left(x_{i}, x_{j}\right) \\
& =\sum_{i=1}^{n} \operatorname{Var}\left(x_{i}\right)+\sum_{i \neq j} \operatorname{Cov}\left(x_{i}, x_{j}\right) \\
& =n+\sum_{i \neq j} \rho_{i j} \\
& =n+\frac{2 n !}{2(n-2) !} \bar{\rho} \\
& =n+n(n-1) \bar{\rho}
\end{aligned}
$$

In addition, we have $\operatorname{Var}\left(\sum_{i=1}^{n} x_{i}\right) \geq 0$, that leads to:

$$
\bar{\rho} \geq-\frac{1}{n-1}
$$

In consequence, for $n=3$, it results in $\bar{\rho} \geq-0.5$, therefore $L_{p}(c) \geq 0.75$. 